\title{
Pre-Exchange Transfusion Administration of Albumin: An Overlooked Adjunct in the Treatment of Severe Neonatal Jaundice?
}

\author{
Charles E Ahlfors \\ Consulting Professor, Department of Pediatrics, Stanford University School of Medicine, Stanford, California 94305, USA. \\ ligand@centurytel.net
}

I $\mathrm{n}$ this issue of Indian Pediatrics, Shahian and Moslehi(1) report that albumin given prior to exchange transfusion in jaundiced but healthy term newborns is associated with significantly lower post-procedure total serum unconjugated bilirubin levels (TSB) and a reduced need for further treatment. Unfortunately, the evidence presented does not support routine administration of albumin prior to exchange transfusion because the actual amounts of bilirubin removed by the procedure are not documented. The bilirubin removed by the procedure is readily obtained by measuring the volume and bilirubin content of the blood discarded during the procedure(2-4). Without these critical data, the study does not prove causation (i.e. that albumin administration was the cause of the difference in outcome).

The post-exchange transfusion or "rebound" TSB is not an appropriate outcome metric for judging the efficiency of an exchange transfusion, regardless of the pre-exchange $\operatorname{TSB}(3)$. The amount of bilirubin removed (the efficiency of the procedure) depends primarily on how much preexchange bilirubin has accumulated in both the extravascular and vascular compartments (the miscible bilirubin pool). Extravascular bilirubin moves into the vascular compartment during the procedure and the degree to which this impacts the post-exchange TSB therefore depends on both the pre-exchange extravascular and vascular bilirubin levels(3). Variability in vascular bilirubin-albumin binding confounds the relationship between TSB and the extravascular bilirubin level(5), and there is no guarantee that the extravascular bilirubin levels were similar in the two study groups despite similar pre-exchange TSB and randomization. The albumin group was admitted on average a day earlier than the controls $(P<0.001)$ and may have accumulated less bilirubin and had lower miscible bilirubin pools (better than average bilirubin-albumin binding would account for the relatively higher TSB around $30 \mathrm{mg} / \mathrm{dL}$ in the vascular space).

It is also difficult to reconcile the differences in post-exchange TSB with the dose of albumin used in this study, particularly since little difference in albumin concentrations was documented between the study groups either before or after the procedure. Assuming the controls had a plasma volume of 1.6 $\mathrm{dL}(0.50 \mathrm{dL} / \mathrm{kg} \times 3.2 \mathrm{~kg})$ and a TSB of $30 \mathrm{mg} / \mathrm{dL}$, the vascular bilirubin available for removal at the beginning of the procedure is $48 \mathrm{mg}$. The postexchange TSB of $21.4 \mathrm{mg} / \mathrm{dL}$ indicates a net removal of about $15 \mathrm{mg}$ of bilirubin (33\% efficiency). If albumin administration (1 $\mathrm{g} / \mathrm{kg})$ transiently increased the albumin from 3.5 to $4.0 \mathrm{~g} / \mathrm{dL}$ and the plasma volume by $10 \%(3,6)$, the maximum preexchange vascular bilirubin available for removal would increase to about $62 \mathrm{mg}(30 \mathrm{mg} / \mathrm{dL} \times(4.0 / 3.5)$ $\times 1.8 \mathrm{dL}$ ), a $29 \%$ increase. In order to obtain a postexchange TSB of $14.4 \mathrm{mg} / \mathrm{dL}$, about $40 \mathrm{mg}$ of bilirubin would need to be removed (65\% efficiency, a $167 \%$ increase in bilirubin removed). This is far beyond the typical efficiency of exchange transfusions(3) and requires documentation with the actual amount of bilirubin removed by the procedure, if we are to conclude that albumin 
administration augmented bilirubin removal to this degree.

Odell, in 1959, verified the hypothesis that vascular bilirubin-albumin binding would cause a shift of bilirubin from the extravascular to intravascular compartment following albumin administration(7). Subsequent studies showed that albumin administration improved the efficiency of exchange transfusion, as measured by the bilirubin removed (not the post-exchange TSB), by up to about $40 \%(2-4,6)$. While albumin may improve the efficiency of exchange transfusion, the improvement has not been overly profound and routine clinical use is not justified by this study. We are also reminded once again that vascular bilirubin-albumin binding limits the use of TSB as an indicator of the size of the miscible bilirubin pool, the magnitude of the ongoing bilirubin production/excretion mismatch, and the overall risk of bilirubin toxicity(5).

Funding: None.

Competing interests: None stated.

\section{REFERENCES}

1. Shahian M, Moslehi MA. Effect of albumin administration prior to exchange transfusion in term neonates with hyperbilirubinemia: a randomized controlled trial. Indian Pediatr 2010; 47: 241-244.

2. Odell GB, Cohen SN, Gordes EH. Administration of albumin in the management of hyperbilirubinemia by exchange transfusions. Pediatrics 1962; 30: 613-621.

3. Valaes T. Bilirubin distribution and dynamics of bilirubin removal by exchange transfusion. Acta Paediatr Scand 1963; 52 (suppl 1149): 1-117.

4. Comley A, Wood B. Albumin administration in exchange transfusion for hyperbilirubinemia. Arch Dis Child 1968; 43: 151-154.

5. Ahlfors CE, Wennberg RP, Ostrow JD, Tiribelli C. Unbound (free) bilirubin (bf): improving the paradigm for evaluating neonatal jaundice. Clin Chem 2009; 55: 1288-1299.

6. Wood B, Comley A, Sherwell J. Effect of additional albumin administration during exchange transfusion on plasma albumin-binding capacity. Arch Dis Child 1970; 45: 69-52.

7. Odell GB. The dissociation of bilirubin from albumin and its clinical implications. J Pediatr 1959; 55: 268-279. 